\title{
CIRCLING ROUND CIRCULAR CHANGE
}

\author{
Thomas ØSTERGAARD ${ }^{1}$ and Cristina DAN ${ }^{2}$ \\ ${ }^{1} \mathrm{VIA}$ Design \\ ${ }^{2}$ Malmö University
}

\begin{abstract}
In the EU, a programme for implementing a circular approach to the Lifestyle and Fashion Industry dealing with the resource challenges of the massive textile-production has been launched. Thus, the industry faces a need for circular and closed-loop approaches and will be challenged in developing and recruiting internal competencies for making the transition from linear to circular production possible. This article explores the assumption of an existing gap between academia - (the fashion designer's roles and potential theories and models) and compares it with the actual practice of the designer's roles in circular transitional processes in the industry. Using a mixed-method approach, combining quantitative with qualitative research methods, this study investigates the actual roles; practice, reality, and performance of the designers in the field of circular design (CD) practice, its relation to the educational background and the designer's circular competences. It reveals huge gaps between theory and practice and an accumulated frustration among the designers on both having a) a lack of mandate order to execute the circular economy (CE) principles, and b) a need for new competences in the business. The paper finally suggests how to use the research when developing Education for Sustainable Development with a focus on design.
\end{abstract}

Keywords: Circular fashion, educations for sustainable development (ESD), design education, circular economy, role of the fashion designer

\section{THE CHALLENGE - INTRODUCTION}

The fashion industry has a substantial contribution to climate change, exercising a high negative environmental and social impact $[1,2,3]$. Design can have a meaningful positive contribution as it is estimated that up to $80 \%$ of the environmental impact of a product is determined at the design stage [4, 5]. Therefore, designers can be seen as "Agents of Change", yet so far, their contribution within companies in the transition towards circularity has been limited. In academia and reports surrounding the research the designers are often identified to be one of the key-professions which could mitigate the immense impacts of the industry and help reduce the impact of the industry through pollution and waste elimination, keeping products and materials in circulation and focusing on regenerating natural systems $[6,7]$. Moreover, circularity requires designers to design for multiple life cycles which in turn appoints numerous new responsibilities $[8,9,6]$. Therefore, the number of responsibilities put on the designer has grown over the past decade. But new studies addressing the performances of fashion designers in CE-transitions show large gaps in circular competences, organisational confusion of roles and tensions in organisations trying to handle the transition $[8,10]$. Other studies show designers lack fundamental sustainable competencies and understanding of challenges in complex systems and a need for refocusing the curricula at design schools in order to enhance the performances of the designers $[11,12$, $8,13]$. This study wishes to investigate if and how fashion designers try to handle the new roles and how their performances in the fashion industry are influenced by surrounding challenges.

\section{THE APPOINTED RESPONSIBLE ROLES IN THE DESIGN-PROCESS}

In fashion, the design process describes the phase in which a piece of clothing or apparel undergoes a wide range of decisive priorities and considerations. The process is considered to contain at least five levels: research, defining the design, prototyping, testing, production, and launch. [7, 14] These phases include crucial decisions deriving from a large number of aspects which are all intertwined and have an impact on the environmental, social, and economic challenges that the final product faces. In the field of circular fashion both non-academic branch-reports, academic research, governmental reports, and 
NGOs tend to consider the designers of the future and present (fast)fashion to be one of the key-point for a new transition towards circular fashion $[14,15]$.

In a CE, the designer's roles include that the designer carries the capacity and competences to handle responsibilities spanning from resource flows, materials use, fibres, chemicals, water usage, lifespan, or lifecycle; end of life processes as well as knowledge about the potential business models for sales, customer use, take back, recycling or reuse [7,10]. Furthermore, as a previous study shows through the ORFDCE model (Organisational Roles of Fashion Designers for Circular Economy) (see Figure 1) the designer can work and possibly interact in different roles in organisations transitioning to a CE, where the designer can have the role of preventing, the role of facilitating and the role of advising, which again should be strategically integrated throughout the different organisational levels [16]. In a CE, organisational systemic changes need to occur in order to enable circularity. [10, 16]. In order for the designer to be aware of and act on some of the above roles, several organisational systemic factors need to be considered: new knowledge on design and context on the part of the designer; dynamic capabilities of the organisation (the company's ability to build, integrate and reconfigure internal and external competences to deal with fast changing surroundings); an improved design management (DM); and a balanced power structure (i.e. the designers' social power as this will largely influence if they have the necessary standing to implement the assigned roles) [16]. Furthermore, as a circular approach relies on collaboration with internal and external stakeholders, sustainability accountability cannot be confined to a single profession $[9,17]$. Moreover, as power within the company must be met as well, creating a new occupational mandate for the designer as Agent of sustainable Change is necessary [18].

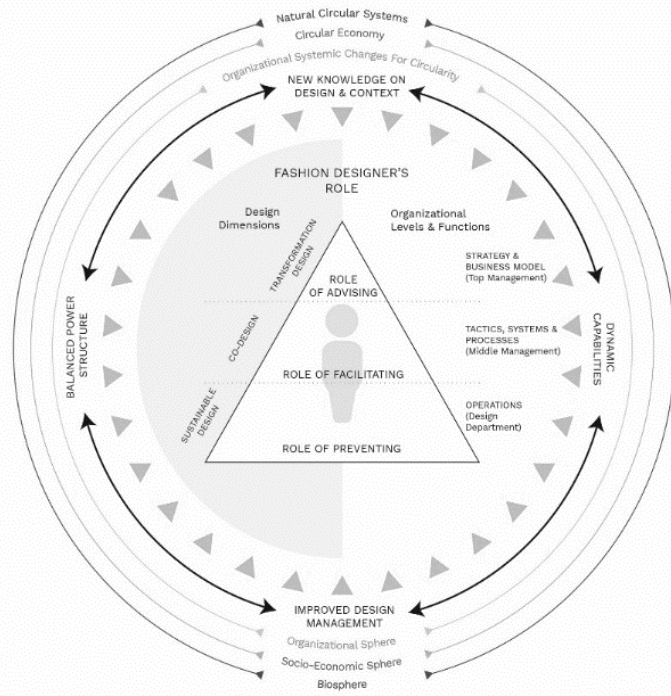

Figure 1. The ORFDCE model, Dan \& Østergaard 2020

\section{PARADOXES AND NEEDS FOR MANAGERIAL ACTIONS}

The challenge of creating a mandate for the designers also calls for a revision of the managerial context in which the designer works. Values and ethos become the centre of attention. When addressing sustainability within organisations, the designer's objectives can be blurred due to organisational tensions and strategic dissonance. Hahn et al. (2014) outlined the inconsideration of organisational tensions and conflicts that contrasted with the convoluted nature of corporate sustainability.[19] Hahn's work emphasized that many businesses today seek simultaneously distinctive sustainability goals even though they can be antagonistic, as formulating a solution to one challenge could be unfavourable to another. As such, the lack of consensus regarding sustainable design not only relates to the lack of knowledge on the designer's part but also the lack of setting a clear set of objectives at the organisational level that are aligned to the company's sustainable vision and mission [20]. Hahn advocates for a transparent managerial approach to corporate sustainability issues, not giving one point of view more value than the other - but persisting on the differences of opinion and thereby generating an "Acceptance Strategy" that can transform existing tensions into "creative tension". This would allow for participation and a more agile open dialogue across the functions in the organisations and the management [19]. Also, Karell and Niinimäki (2020) conclude that designers more or less are struggling with the challenges of 
"business tensions" and uncertainty of mandates, roles, and functions. But unfortunately, this knowledge has not been included in the industry's practices.

\section{METHODOLOGY}

The intention of this article is on one hand to explore the assumption of an existing gap between academia - (fashion designer roles and potential theories and models) and the actual practice of the designer's roles in circular transitional processes in the industry. By using a mixed-method approach, this study combines quantitative (surveys) with qualitative research methods (semi structured interviews). [21] Data analysis was conducted in two stages. Firstly, a survey was sent to 20 fashion designers working in sustainable-minded medium-sized Danish companies, of which nine responded. As the survey contained mostly open-ended questions, the analysis was conducted through qualitative content analysis where common themes were identified and coded. In the second stage of the sequential mixed method exploratory strategy $[22,21]$ five semi-structured in-depth interviews were conducted with five fashion designers working for sustainable-minded fashion companies in Denmark. This was done in order to gain closer insight into the challenges of the roles, mandates, and appointed responsibilities of the designer. The data was analysed through thematic analysis which allowed to identify common and/or varying patterns of practices. Then, the interview results were compared to those of the survey. In order to zoom out in perspective on the inputs from the data, two supplementary in-depth interviews with $\mathrm{CE}$ branch experts were conducted.

Table 1. The occupation, company type and experiences of the interviewed designers and
experts

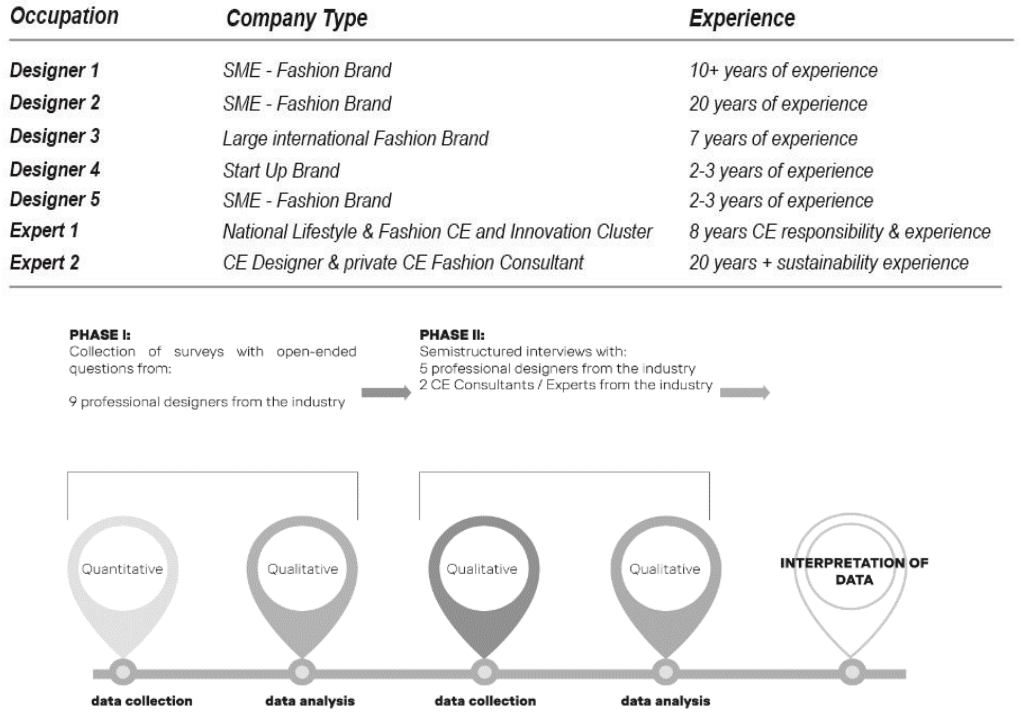

Figure 2. Sequential exploratory study strategy

The designers from both research stages were identified and contacted through and in collaboration with the national Danish Hub for Innovation in the Textile Sector; the Lifestyle and Design Cluster (LDCluster) for a more precise selection of respondents. But, as this study also shows, similar to other studies made by Karell, E. \& Niinimäki (2020) it can be really difficult to find designers who are willing to a; spend the time on the interview, and b; commit themselves to a longer lasting relationship to research. $[22,21]$. Therefore, the study has certain limitations and would have benefitted from more interviews and survey responses that would have enriched and brought more nuance to the data.

\section{FINDINGS}

Both interviews and surveys had the primary objective of identifying challenges of the roles, mandates, and appointed responsibilities of the designer within organisations that are sustainable-minded. The questions asked were similar for both interviews and surveys and addressed: experience with $\mathrm{CE}$ and $\mathrm{CD}$ and competencies, obstacles they encountered in implementing $\mathrm{CD}$, support, and opportunity within the company to exercise real changes in relation to sustainable development and $\mathrm{CE}$, new roles and responsibilities, organisational challenges, and tensions. Three thematic clusters were identified below: 


\subsection{Roles}

Outlining main findings, all but one designer confirmed that the company they work with has started working with $\mathrm{CE}$ and themselves with $\mathrm{CD}$, but they are only in the incipient stage. When asked, if the designers have the skills to work with $\mathrm{CE}$ and $\mathrm{CD}$ today, six respondents of the survey said they were poorly prepared and pointed at the need for new knowledge and life-long learning opportunities; but also the need for new cross-departmental collaborations between the design department and the purchasers and management. When asked; "Do you feel that the designer has been given more responsibilities in connection with sustainable production and CE?" replies showed new areas of responsibility have emerged over to the designer's field. On the other hand, more than half of the respondents still replied their roles were unchanged and their influence rather limited. In the designer's area, managerial decisions and interests are still key. When questioned if the designers felt they had a substantial influence on making the companies more sustainable the replies differed, but most described a limited discussion with the management. Only a couple of the designers saw themselves as leaders towards circular economy in their companies. The three main obstacles to implementing CD in their business or industry were: poor communication of strategies and communication between departments in the business, followed by a lack of competences and finally uncertainty of roles and mandates in decision making. In the in-depth interviews, the designers pointed at a sense of being "left alone" - or considered to be an idealist, as the CE and sustainable aims were not integrated into the practice of all the business departments. Moreover, due to lack of time allocation, there is a considerable gap in the designer's CE and CD knowledge. Furthermore, as one designer pointed out: "the designer can do something today, but once we work with systemic interventions, there is a need for the designer to be part of broad interdisciplinary teams in the companies".

\subsection{Mandate}

When asked if the designers felt they have the right "mandate" - that is, a legitimate opportunity to act and launch real changes in sustainable development and the circular economy strategy within the company, the replies differed. Only two of the respondents replied with a full "yes" - whereas most of the respondents said they lacked mandate to act, as the communication between the design department and the management level was poor. As one designer stated, "I have in principle the mandate to work with CE but lack support from procurement and management".

More than a quarter of the respondents found it crucial that candidates from the design schools are trained in CE-competences with half of them saying it is crucial for hiring them and four of them saying it is definitively important for hiring them. A majority of the interviewed designers from the in-depth sessions stated that there is a) a lack of true commitment from the management towards sustainability and in particular CE., b) there is a lack of understanding of what sustainability is more than just a buzzword or marketing effect amongst the management, c) there is a lack of genuine interest in transforming the present business models, sourcing techniques, value chains or materials in use from the management, as the legislation still is fairly vague and encourages the present fast-fashion linear production.

\subsection{Organisational tensions}

All survey respondents and interviewees recognize tensions within the organisations they work in as CE begins to be integrated within the company including management level. As designers call out several aspects when asked if sustainability and CE can create tensions between different departments and actors in the company: "Yes, many and great tensions between Design and Economy", "Greatly. Sustainable production challenges our value chain and our entire design."

\section{DISCUSSION}

On one hand, the in-depth interviews with the designers showed how prior research on the potential of the designers' roles are dependent on the organisational levels and design dimensions and the power that the designer is offered or able to use [16]. When asked if the designer could see a role as "adviser" on organisational, managerial level, the role of facilitator on a systemic and processual level or the role of preventing on an operational level only few of the interviewed found they had the time, the competences, and mandates to act accordingly. But to the designers these roles could be relevant and of importance, dependent on radical organisational changes, involving all the departments of the business. So, the necessity of a holistic approach for both understanding the organisational system and the external influences on the designer's role is obvious. 
Moreover, this study is in accordance with the previous research made by Sumter et al. 2020 and Karell and Niinimäki (2020) showing organisational confusion of roles and tensions in organisations trying to handle the transition $[8,10]$, but it also reveals the need for new research on other levels of the fashion organisations: management, purchasing, marketing, sourcing, economy, and investment strategies and how these silos in the organisations can collaborate. These types of interactions and breaking of silos should firstly start to appear within the curricula of design educational institutions, setting an example and direction for future practices within organisations.[12] Moreover, the study shows the fashion industry has stalled and probably will not deliver the expected reduction on the impact of the industry, unless political and legislative initiatives become reality.

Corporate tensions in the organisations between designers and other departments showed to be widely spread, with very different aims and approaches to sustainability and circular economy in practice. The commercial sales team and the marketing team in a company, are, according to the designers, not necessarily interested or concerned with sustainable issues at the same level as the design department. In these areas of the business, sustainability is often considered, treated, and communicated as a "trend" - or a strong sales promotion and thereby confusing the overall intention of sustainable products or circular initiatives even more.[19]

The interviewed designers expressed a clear need for leadership but also a profound confusion on who has the mandate to generate change and who is actually responsible. Again, and again the designers pointed at other areas in the company than the design department as the decision making, strategy making or financially decisive. More than half of the interviewees stated their roles had not changed over the past 5-10 years and that their roles still relied on traditional non-sustainable design virtues.

Finally, the educational aspects on CE-competences appear to be crucial for new fashion design organisational positions as they begin to include a circular mandate. And here some of the key answers to why the industry lacks to change is maybe to be found. Here we seem to find a pattern of connections.

\section{CONCLUSIONS}

The intention of this pilot-study has been to try to help identify and bridge the perspectives of academia within the field of circular economy and sustainable development with the fashion industry's current practice, in a mutually beneficial way.

This pilot-study shows a series of gaps between the designer's perception of their roles and the cultural and organisational norms that surround them. And this may be in contrast to the picture of the designer as potentially "Agent of Change". The interviewed designers have been far away from research and academia for some years, and most of them were not aware of the expected roles in CE or CD. The dominating business structures of fast fashion and organisational power, restrains the designers within the conditions they work. The following points were repeated by the interviewed designers: a) need for radical political and industrial legislative action - legislation is lacking and if the change towards a circular fashion industry is to take place, management will only commit if there are legal requirements and clear regulations on the industry; $b$ ) competencies, knowledge and transparency - competences and knowledge about sustainability and circularity is evidently something most of the designers have made on their own, mostly unaware of existing tools and with limited time to research further into the capacities of these models. Hence, the competences and knowledge are far away from the level of the present academia. It became clear that some of the designers, even if they are adapting circular or sustainable design principles, still rely strongly on a linear production value-chain. The designers also expressed a basic need for knowledge, inputs, and cross-disciplinary collaboration from and with specialists and researchers within materials, chemistry, engineering, technology, and circular business models; c) time and the provision of Sustainable Collaborative teams - time was a recurring theme for the interviewed participants and a significant challenge in order to enhance change. So, the mere thought of adding more circular responsibilities to the present tasks seemed unrealistic. In this way, the picture of the designer as the central organisational circular hub is crashing. Building new organisational structures that facilitate the creation of new teams relying on different skills and competences may on one hand provide an opportunity to identify and distribute circular tasks and add interdisciplinarity to the teams, but also require huge investments and re-organisations of the industry. And, finally, a closer, trustful, and continuous collaboration with research and academia is needed, in order to learn from, share and analyse the practices and potentials of the sector.

If the society surrounding the fashion industry has had the hope of the designer as the potential Agent of Change, this study stresses the overall need for education at all organisational levels in the fashion 
industry. Right now, it appears there are only a few agents of change and no agents of the community, but a dominant level of agents of profit. This calls for new research on educational practices.

\section{REFERENCES}

[1] Fletcher K. 2010. "Slow Fashion: An Invitation for Systems Change". Fashion Practice The Journal of Design, Creative Process \& the Fashion Industry, 2(2), 259-265.

[2] Gwilt A. 2014. A practical guide to sustainable fashion. Fairchild Books, an imprint of Bloomsbury.

[3] Roos S., Jönsson C., Posner S., Arvidsson R., and Svanström M. 2019. "An inventory framework for inclusion of textile chemicals in life cycle assessment." The International Journal of Life Cycle Assessment, 24(5), 838-847.

[4] European Parliamentary Research Services. The Ecodesign Directive. 2017.

[5] European Commission. 2020. Circular Economy Action Plan.

[6] Buchel S., Roorda C., Schipper K., and Loorbach D. (2018). Drift for transition. The transition to good fashion. Fashion for Good.

[7] EMF (Ellen MacArthur Foundation). 2017. A new textiles economy. Redesigning fashion's future.

[8] Sumter D., de Koning J., Bakker C., and Balkenende R. (2019). Design competencies for a circular economy. In N. F. Nissen, \& M. Jaeger-Erben (Eds.), 3rd Product Lifetime and the Environment (PLATE) 2019 (pp. 1)

[9] Pedersen E. R. G., Earley R., and Andersen K. R. (2019). From Singular to Plural: Exploring Organisational Complexities and Circular Business Model Design. Journal of Fashion Marketing and Management, 23(3), 308- 326.

[10] Karell E. and Niinimäki K. (2020), A Mixed-Method Study of Design Practices and Designers' Roles in Sustainable-Minded Clothing Companies, Sustainability 2020, 12, 4680.

[11] Østergaard T. 2018. "The Designer as Agent of Community." In ServDes.2018 Service DesignProof of Concept p 76-91. Linköping University Electronic Press, Linköpings universitet.

[12] Østergaard T. (2019) Revising Creative Sustainability-competencies in Design Educations: The Future of Design. 1 Ed. p. 13-19 6 p. 13-19

[13] Leube M. and Walcher D. 2017. "Designing for the next (Circular) Economy. An appeal to renew the Curricula of Design Schools." The Design Journal, S492-S501.

[14] EMF (Ellen MacArthur Foundation). 2012. Towards the circular economy Vol. 1: an economic and business rationale for an accelerated transition. EMF (Ellen MacArthur Foundation).

[15] Lewis H., Gertsakis J., Grant T., Morelli N. and Sweatman A. 2017. Design+environment: a global guide to designing greener goods. Routledge.

[16] Dan M. C. and Østergaard T. (in press). Circular fashion: the new roles of designers in organisations transitioning to a circular economy. The Design Journal.

[17] Hvass K. and Pedersen E. R. G. (2019). Toward circular economy of fashion: Experiences from a brand's product take-back initiative. Journal of Fashion Marketing and Management: An International Journal, 23(3), 345-365.

[18] Fayard A.-L., Stigliani I., and Bechky B. A. (2017) How Nascent Occupations Construct a Mandate: The Case of Service Designers' Ethos, Administrative Science Quarterly 2017, Vol. 62(2)270-303.

[19] Hahn T., Preuss L., Pinkse J., and Figge F. 2014. Cognitive Frames in Corporate Sustainability: Managerial Sensemaking with Paradoxical and Business Case Frames. Academy of Management Review, 39(4): 463-487.

[20] Hur E. and Cassidy T. (2019). Perceptions and attitudes towards sustainable fashion design: Challenges and opportunities for implementing sustainability in fashion. International Journal of Fashion Design, Technology and Education, 12(2), 208-217.

[21] Creswell J. W. Research Design: Qualitative, Quantitative and Mixed Methods Approaches, 3rd ed.; SAGE Publications, Inc.: Thousand Oaks, CA, USA, 2009.

[22] Lund T. Combining qualitative and quantitative approaches: Some arguments for mixed methods research. Scandinavian Journal of Educational Research 2012, 56, 155-165. 